\title{
Management of Parapneumonic Effusion and Empyema: Medical Thoracoscopy and Surgical Approach
}

\author{
Lukas Kern $^{\mathrm{a}}$ John Robert ${ }^{\mathrm{b}}$ Martin Brutsche ${ }^{\mathrm{a}}$

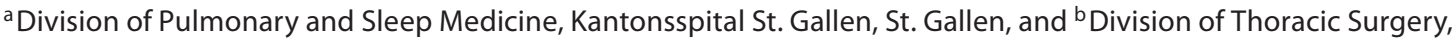 \\ University Hospital of Geneva, Geneva, Switzerland
}

\section{Key Words}

Parapneumonic effusion - Empyema - Chest tube drainage $\cdot$ Medical thoracoscopy $\cdot$ Video-assisted thoracic surgery $\cdot$ Thoracotomy

\begin{abstract}
Parapneumonic effusions or empyemas are frequently seen in patients with lower respiratory tract infections. The condition is associated with significant morbidity and mortality. Since Gram stains and bacterial cultures are usually negative, treatment focuses on empiric antibiotic treatment and chest tube drainage. The role of intrapleural fibrinolytics is still a matter of debate. Medical thoracoscopy is a simple and effective therapeutic alternative associated with better outcome and fewer complications than conservative treatment. Furthermore, it can be performed in analgo-sedation in a bronchoscopy suite. Video-assisted thoracic surgery carries the advantage of providing optimal visibility of the pleural cavity, thus allowing better debridement. Thoracotomy is the treatment of choice when thoracoscopic cleaning is not satisfactory.

Copyright $\odot 2011$ S. Karger AG, Basel
\end{abstract}

\section{Introduction}

Lower respiratory tract infections are mainly treated by general practitioners in an outpatient setting. However, in patients hospitalized for lower respiratory tract infection, parapneumonic effusions occur in up to $57 \%$ of patients [1]. A progression to complicated parapneumonic effusion and empyema has been demonstrated to occur in $6 \%$ of patients [2]. This complication is associated with significant morbidity as well as mortality and results in significant costs. Immediate treatment is of great importance, since short time to antibiotic treatment is demonstrated to be a significant predictor of outcome and is associated with increased survival in patients with community-acquired pneumonia [3, 4]. Empyema is associated with significant morbidity and mortality. Different studies show mortality rates of up to $30 \%$ [5-7]. Treatment modalities will be discussed below, but consist primarily in the drainage of the effusion and antibiotics. In the case of failure of a conservative approach due to the inability to evacuate pleural fluid accumulation, treatment consists of either medical thoracoscopy, video-assisted thoracic surgery (VATS) or thoracotomy, and exceptionally, thoracostomy. Until now and due to the lack of large prospective studies, there is no clear-cut agreement on the role of thoracoscopy in the handling of para-

Dr. Lukas Kern, MD

Division of Pneumology and Sleep Medicine, Cantonal Hospital St. Gallen Rorschacherstrasse 95 CH-9007 St. Gallen (Switzerland)

E-Mail lukas.kern@kssg.ch 
Table 1. Risk stratification scale as proposed by the ACCP (adapted)

\begin{tabular}{|c|c|c|c|c|c|c|c|}
\hline Pleural space anatomy & & Pleural fluid bacteriology & & $\mathrm{pH}$ & Category & Risk & Drainage \\
\hline $\begin{array}{l}\text { Minimal effusion } \\
\text { ( }<10 \mathrm{~mm} \text { on lateral decubitus) }\end{array}$ & and & $\begin{array}{l}\text { cultures and Gram stain } \\
\text { results unknown }\end{array}$ & and & unknown & 1 & very low & no \\
\hline $\begin{array}{l}\text { Small to moderate effusion } \\
(<10 \mathrm{~mm} \text { and }<1 / 2 \text { hemithorax })\end{array}$ & and & $\begin{array}{l}\text { negative culture and } \\
\text { Gram stain }\end{array}$ & and & $\geq 7.2$ & 2 & low & no \\
\hline $\begin{array}{l}\text { Large effusion } \\
(<1 / 2 \text { hemithorax loculated effusion } \\
\text { or thickened parietal pleura) }\end{array}$ & & pus & & & 4 & high & yes \\
\hline
\end{tabular}

pneumonic effusions and/or empyema. The recommendations described in this article reflect the results of recent research as well as our experience in this field.

\section{Guidelines and Diagnostic Approach}

The approach to the patient with parapneumonic effusion and empyema has been standardized by experts of the American College of Chest Physicians (ACCP) [5] as well as the British Thoracic Society (BTS) [8]. Both guidelines include recommendations regarding thoracic surgery, but not medical thoracoscopy. The most important feature of the ACCP guideline [5] is the provision of a scale to stratify the risk for poor outcome in terms of mortality, respiratory failure, prolonged hospitalization and inflammation (table 1). Patients are stratified according to 3 different variables: anatomy of the pleural space, bacteriology of the effusion and chemical composition of the effusion. Presence of pus was associated with the highest risk. Nowadays, stratification is mostly done using chest ultrasound to estimate total liquid volume, echogenicity of the liquid, the extent of septation, and the degree of impairment of the diaphragmatic motility [2]. The recently published BTS guidelines [8] provide a diagnostic and therapeutic algorithm allowing rapid decision making not only upon presentation of a new case but also during treatment. In general, empyema is defined either by the presence of frank pus upon puncture or by an effusion with documented microorganisms under direct microscopy [5]. However, bacterial cultures are mostly negative, probably due to the heterogeneous distribution of the effusion caused by massive loculation and by antibiotics. Ultrasound-guided puncture of pleural effusions is safe and yields sufficient information in order to stratify patients.

\section{Treatment}

\section{Conservative Approach}

Treatment is primarily based upon antibiotics and complete drainage of the effusion. Both ACCP and BTS guidelines recommend chest drainage of effusions with a $\mathrm{pH}<7.2[5,8]$, since $\mathrm{pH}$ has been identified to be the most important factor needed for the decision of whether chest drainage is indicated [6]. Chest tube drainage is an effective treatment. The failure rate of a conservative treatment approach was only $6 \%$ in a large German case series, along with a mortality rate of only $4 \%$ [9]. Although there is no consensus about the optimal size of chest catheters, physicians tend to use large bore catheters for pleural infections to avoid blockage. In contrast, the 2010 BTS guidelines recommend the use of small bore (10-14 Fr) catheters and repetitive rinsing to avoid blockage [8]. In addition, insertion of the chest tube is recommended to be performed under visual guidance. Serial thoracentesis might be an alternative to chest drainage, but its role remains unclear and controversial. One study demonstrated the success of serial thoracentesis in the treatment of empyema [10]. The role of fibrinolytics as an adjunct to chest drainage has been widely discussed. A clear benefit of fibrinolytics could not be found in a large meta-analysis by Tokuda et al. [11] and neither in a Cochrane Review from 2008 [12]. Although some studies have reported promising results and fibrinolytics may provide benefit to individually selected patients, the routine use of fibrinolytics is not recommended by the BTS [8].

\section{Medical Thoracoscopy}

Medical thoracoscopy has played a marginal role in the treatment of empyema for a long time, but has become more and more established in recent years. It can be per- 
formed in analgo-sedation in a bronchoscopy suite. It is minimally invasive and costs are much lower compared to surgical VATS. The diagnostic and therapeutic power seems to be comparable to VATS, since several studies show success rates with medical thoracoscopy between 73 and $100 \%$ [2, 13-15]. In general, complication rates, which consisted mainly of bleeding and air leaks, were reported being low, with an incidence between 0 [16] and $16 \%$ [17]. Like VATS, medical thoracoscopy can be performed using multiple ports in order to aspirate liquid, to disrupt fibrinous membranes, to open loculations, and finally, to inspect and cleanse the pleural cavity. On the other hand, VATS is certainly superior in the case of severe loculation and the presence of organized septae containing blood vessels. Furthermore, pleurectomy, lung suture or wedge resection can only be achieved by VATS or thoracotomy.

\section{The Thoracic Surgeon's Approach to Complicated}

Parapneumonic Effusions and Empyemas

When dealing with parapneumonic effusions which form the bulk of pleural empyemas [18] and the subject of this review, one should keep in mind that empyemas can occur in totally different settings such as after chest trau$\mathrm{ma}$, in tumorous diseases (usually pleural, such as mesotheliomas), after lung resection procedures or other types of surgery, such as cardiac or esophageal procedures. Therapeutic approaches to all of these may differ. The following remarks apply only to parapneumonic effusions.

As with many other pathologies which occasionally end up in the operating room, cases of parapneumonic effusions are usually handled first by internists or pulmonologists, and more often than not, in a successful manner. Decision and timing of surgery - when deemed necessary - are thus occasionally postponed. When the situation is felt to deserve surgical handling, the first prerequisite is obviously pleural drainage. In order to permit evacuation of fluids which are frequently thick, physi- cians usually prefer large bore drains, even if the recent BTS guidelines [8] seem to show small catheters (10-14 Fr) to be just as efficient. Drains should obviously be placed in the proper spot and when CT shows the pleural collection to be large and unique, a drain placed posteriorly should suffice. But in case of multi-loculated collections, CT- or ultrasound-guided drain placement is preferred. Due to recent studies, fibrinolytics are not generally recommended $[5,8]$ for the standard clinical practice, but might be useful in specific cases.

Surgery now is a cleaning debridement-like procedure which can usually be achieved by thoracoscopy in experienced hands [19], all the more so if performed early in the course of the disease (delay may lead to chronic empyema which is a totally different story) [20]. So-called 'medical' thoracoscopy seems a bit ambitious in this setting as the lung cannot be excluded (patients are not intubated) and pain control may be inefficient when scrubbing sensitive parietal pleurae.

If thoracoscopy cannot achieve satisfactory cleaning, an open but short thoracotomy should be resorted to without hesitation. Given the fact that patients are frequently spared epidural catheters, intercostal spaces adjacent to the opening can easily be infiltrated with local anesthetics.

The postoperative course is usually uneventful on a septic level, even if the first postoperative X-rays frequently appear desperately blurred. Antibiotics should be continued after surgery, intravenously during the first days, and orally thereafter for approximately 2 weeks. Ideally, antibiotics should conform with the antibiogram when a germ has been identified (which is not always the case) [19]. While exceptional, recurring empyema may require more aggressive procedures, such as open-window thoracostomies (the Eloesser flap [21]), for instance when bronchopleural fistulae are not amenable to surgical repair. Another quicker way is represented by longlasting indwelling catheters [18].

\section{References}

${ }_{1}$ Taryle DA, Potts DE, Sahn SA: The incidence and clinical correlates of parapneumonic effusions in pneumococcal pneumonia. Chest 1978;74:170-173.

2 Brutsche MH, Tassi GF, Gjörik S, et al: Treatment of sonographically stratified multiloculated thoracic empyema by medical thoracoscopy. Chest 2005;128:3303-3309.
3 Meehan TP, Fine MJ, Krumholz HM, Scinto JD, Galusha DH, Mockalis JT, Weber GF, Petrillo MK, Houck PM, Fine JM: Quality of care, process, and outcomes in elderly patients with pneumonia. JAMA 1997;278: 2080-2084

4 Houck PM, Bratzler DW, Niederman M, Bartlett JG: Pneumonia treatment process and quality. Arch Intern Med 2002;162:843844.
5 Colice GL, Curtis A, Deslauriers J, et al: Medical and surgical treatment of parapneumonic effusions: an evidence-based guideline. Chest 2000;118:1158-1171.

6 Heffner JE, Brown LK, Barbieri C, et al: Pleural fluid chemical analysis in parapneumonic effusions. A meta-analysis. Am J Respir Crit Care Med 1995;151:1700-1708. 
Sasse SA: Parapneumonic effusions and empyema. Curr Opin Pulm Med 1996;2:320326.

8 Davies HE, Davies RJ, Davies CW, BTS Pleural Disease Guideline Group: Management of pleural infection in adults: British Thoracic Society Pleural Disease Guideline 2010. Thorax 2010;65(suppl 2):ii41-ii53.

$>9$ Loddenkemper R, Kaiser D, Frank W: Treatment of parapneumonic pleural effusion and empyema: conservative view. Eur Respir Mon 2004;29:199-207.

-10 Storm HK, Krasnik M, Bang K, et al: Treatment of pleural empyema secondary to pneumonia: thoracocentesis regimen versus tube drainage. Thorax 1992;47:821-824.

-11 Tokuda Y, Matsushima D, Stein GH, et al: Intrapleural fibrinolytic agents for empyema and complicated parapneumonic effusions: a meta-analysis. Chest 2006;129:783-790.
12 Cameron R, Davies HR: Intra-pleural fibrinolytic therapy versus conservative management in the treatment of adult parapneumonic effusions and empyema. Cochrane Database Syst Rev 2008;2:CD002312.

13 Solèr M, Wyser C, Bolliger CT, et al: Treatment of early parapneumonic empyema by 'medical' thoracoscopy. Schweiz Med Wochenschr 1997;127:1748-1753.

14 Colt HG: Thoracoscopy. A prospective study of safety and outcome. Chest 1995;108:324329.

15 Reynard C, Frey JG, Tschopp JM: Thoracoscopie en anesthésie locale dans le traitement des empyèmes: une technique efficace et peu invasive. Med Hyg 2004;62:2138-2143.

16 Cassina PC, Hauser M, Hillejan L, et al: Video-assisted thoracoscopy in the treatment of pleural empyema: stage-based management and outcome. J Thorac Cardiovasc Surg 1999; 117:234-238.
7 Angelillo Mackinlay TA, Lyons GA, Chimondeguy DJ, et al: VATS debridement versus thoracotomy in the treatment of loculated postpneumonia empyema. Ann Thorac Surg 1996;61:1626-1630.

18 Molnar TF: Current surgical treatment of thoracic empyema in adults. Eur J Cardiothorac Surg 2007;32:422-430.

19 Lee SF, Lawrence D, Booth H, et al: Thoracic empyema: current opinions in medical and surgical management. Curr Opin Pulm Med 2010;16:194-200.

20 Shiraishi Y: Surgical treatment of chronic empyema. Gen Thorac Cardiovasc Surg 2010;58:311-316.

21 Eloesser L: An operation for tuberculous empyema. Surg Gynecol Obstet 1935;60:10961097. 